\title{
The Outcome of Turning Factors on the Machining Characteristics While Turning 655M13 Steel Alloy using Tialn Coated Carbide Insert
}

\author{
Venkatesh.P, C.Ramesh Kannan, Milon Selvam Dennison
}

\begin{abstract}
This exploration is carried out to reveal the outcome of turning factors such as cutting velocity, depth of cut and feed rate on the surface roughness, mean cutting force and tool-work interface temperature on turning cylindrical 655M13 steel alloy components. The experiments are designed based on (33) full factorial design and conducted on a turning centre with Titanium Aluminium Nitride (TiAIN) layered carbide tool of $0.8 \mathrm{~mm}$ nose radius, simultaneously cutting forces such as feed force, thrust force and tangential force and the tool-work interface temperature are observed using calibrated devices. The surface roughness of the turned steel alloy parts is deliberated by means of a precise surface roughness apparatus. Prediction models are created for average surface roughness, mean cutting force and tool-work interface temperature by nonlinear regression examination with the aid of MINITAB numerical software. The optimum machining conditions are confirmed with the aid of a Genetic Algorithm. The outcome of each turning factor on the surface roughness, mean cutting force and tool-work interface temperature is studied and presented accordingly.
\end{abstract}

Keywords : 655M13; Lathe; Surface roughness; cutting force; TiAIN; Genetic Algorithm; Regression analysis

\section{INTRODUCTION}

The achievement of high quality, in terms of workpiece dimensional accuracy, surface finish, high production rate, less wear on the cutting tools, economy of machining in terms of cost-saving and to increase the performance of the product with reduced environmental impact are the main and effective challenges of modern metal cutting and machining industries (Sharma et al., 2016; Selvam et al., 2016; Krolczyk et al., 2017). Traditionally, hardened steels are machined by grinding processes due to their high strength and wear resistance properties but grinding operations are

Revised Manuscript Received on February 05, 2020.

* Correspondence Author

Venkatesh.P*, Research Scholar, Department of Mechanical Engineering, Karpagam Academy of Higher Education, Coimbatore-641021, INDIA. Email: venkatesh.aeemtneb@gmail.com

C.Ramesh Kannan, Associate Professor, Mechanical Engineering, Karpagam Academy of Higher Education, INDIA. Email: crkannanmech@gmail.com

Milon Selvam Dennison, Mechanical Engineering, Kampala International University, Kampala, UGANDA. Email: milon.selvam@kiu.ac.ug

(C) The Authors. Published by Blue Eyes Intelligence Engineering and Sciences Publication (BEIESP). This is an open access article under the CC BY-NC-ND license (http://creativecommons.org/licenses/by-nc-nd/4.0/) time-consuming and limited to the range of geometries to be produced (Zhang and Liu, 2017; Khan and Bhivsane, 2018). In recent years, machining the hardened steel in turning which uses a single-point cutting tool has replaced grinding to some extent for such application (Mia and Dhar, 2016, Bains et al.,2016). This leads to reducing the number of setup changes, product cost and ideal time without compromising on surface quality to maintain competitiveness (Paul et al., 2016; Selvam et al., 2016).

Titanium-based coatings provided to the cutting tool is familiar in the steel alloy machining due to its hard thin layer deposited onto the base tool. Titanium Aluminium Nitride (TiAlN) is a very fashionable coating applied to the carbide cutting tool insert because TiN acquires some useful properties such as elevated hardness, elevated strength, elevated chemical stability, tremendous resistance to Built-Up Edge formation, little coefficient of friction. Thus, while machining steel alloys TiAlN coated carbide tool inserts could be applied at higher feed rates and cutting velocities (Khorasani et al., 2016; Selvam et al., 2016)

Many practitioners and research personalities are working in the field of machining of steel alloy with TiAlN coated carbide insert, few are presented below;

Bhattacharya et al., (2009) employed Design of Experiment (DoE) to explore the impact of factors on surface roughness and forces during rapid machining of AISI 1045 steel by TiN covered carbide device. Speed was the huge factor in surface roughness and cutting force, while feed and depth of cut did not generously influence the outcome. Aggarwal et al., (2008), Nur et al., (2017) analyzed the cutting force in turning of compound steel utilizing TiN covered carbide embed with DoE approach. The cryogenic condition was the most critical factor in minimizing the cutting force pursued by cutting speed and depth of cut. The possessions of feed rate and nose radius were observed to be less important on the outcome. Cakir et al., (2009), Asiltürk et al., (2016) made a logical representation for surface roughness in machining of compound steel by TiN covering on carbide embed by Chemical Vapor Deposition (CVD) technique. Higher feed rates conveyed higher surface roughness esteems while the factor speed had contrary outcome and depth of cut did not basically impact.

Many researchers and practitioners adapted Design of Experiment (DoE) technique for planning the experiments in the turning of medium carbon steel alloy, few were discussed in the below section; 
The Outcome of Turning Factors on the Machining Characteristics While Turning 655M13 Steel Alloy using Tialn Coated Carbide Insert

Yang et al., (2017) investigated the processing factors in turning and created a predictor for surface roughness using DoE. Their experimentation reveals the feed was the most prominent factor in roughness, trail by cutting speed. The same result was validated through experimentation by, Zerti et al., 2017.

Xiao et al., (2017) analyzed the consequence of speed, depth of cut and feed towards the surface finish by ANOVA and regression model. It is suggested that feed has the utmost influence on the surface finish compared to depth of cut and speed.

Mia and Dhar (2017) analyzed the surface finish in turning of steel and found that the material hardness was the most affecting factor on surface finish and interface temperature and increasing cutting speed leads to achieving a good surface finish with high-pressure coolant condition.

From the journalism expressed above, it turns out to be certain that machining investigations have been completed by different specialists in the field of machining metals. In any case, there stays some trouble in the machining of metal, which uncovers that still additional investigation must be done to locate a sensible arrangement. In this way, the examination of machining is completed by making utilization of the demonstrated test plan method.

\section{EXPERIMENT DETAILS}

The details of the experiment of this research work are specified in Table 1.

Table 1: Experiment details

\begin{tabular}{|l|l|}
\hline \multicolumn{1}{|c|}{ Condition } & \multicolumn{1}{c|}{ Specification } \\
\hline Workpiece material & $655 \mathrm{M} 13$ \\
\hline $\begin{array}{l}\text { The geometry of the } \\
\text { workpiece }\end{array}$ & $\phi 80 \mathrm{~mm} \times 150 \mathrm{~mm}$ \\
\hline Cutting tool used & TiAlN coated carbide insert \\
\hline Machine tool & Turning centre \\
\hline Cutting fluid & Mineral-based (Servocut 'S') emulsion \\
\hline $\begin{array}{l}\text { Coolant application } \\
\text { technique }\end{array}$ & Flooded (wet) \\
\hline $\begin{array}{l}\text { Planning of the } \\
\text { experiment }\end{array}$ & Full factorial design ( $3^{3}=27$ experiments) \\
\hline Optimization technique & Genetic Algorithm \\
\hline Output response & $\begin{array}{l}\text { Surface roughness, mean cutting force and } \\
\text { tool-work interface temperature }\end{array}$ \\
\hline
\end{tabular}

\section{A. Work Piece}

Cylindrical workpiece prepared of 655M13 steel with a size of $(\phi 80 \mathrm{~mm} \times 150 \mathrm{~mm})$ was preferred for this research. $655 \mathrm{M} 13$ is a nickel-chromium steel alloy and is used for the manufacture of the main axis, gear shaft, valve rods, mechanical gears, connecting rods, multi-diameter shafts, nuts, and bolts. The chemical composition of 655M13 steel is given in Table 2.

Table 2: Chemical composition

\begin{tabular}{|c|c|c|}
\hline \multirow{2}{*}{ Element } & \multicolumn{2}{|c|}{ \% Composition } \\
\cline { 2 - 3 } & Standard & Tested \\
\hline $\mathrm{C}$ & $0.1-0.2$ & 0.170 \\
\hline $\mathrm{Ni}$ & $2.75-3.25$ & 3.120 \\
\hline $\mathrm{Cr}$ & $0.6-0.95$ & 0.870 \\
\hline $\mathrm{Mn}$ & $0.3-0.5$ & 0.410 \\
\hline $\mathrm{P}$ & $0.04 \mathrm{max}$ & 0.030 \\
\hline $\mathrm{Si}$ & $0.15-0.3$ & 0.270 \\
\hline $\mathrm{S}$ & $0.05 \mathrm{max}$ & 0.041 \\
\hline $\mathrm{Fe}$ & Rest & 95.090 \\
\hline
\end{tabular}

\section{B. Cutting Tool}

A universal CNMG diamond finishing TiAlN layered carbide insert of $0.8 \mathrm{~mm}$ nose radius and PCLNR tool holder was utilized to do the turning operation on 655M13 steel components.

\section{Cutting Fluid}

Mineral oil blended with a stream of water was utilized as cutting fluid for this investigation. The properties of the base oil are specified in Table 3.

Table 3: Properties of Oils

\begin{tabular}{|l|c|}
\hline \multicolumn{1}{|c|}{ Property } & Value \\
\hline Flash Point $\left({ }^{\circ} \mathrm{C}\right)$ & 150 \\
\hline Kinematic Viscosity at $40^{\circ} \mathrm{C}(\mathrm{cSt})$ & 20 \\
\hline Specific gravity (No Unit) & 0.877 \\
\hline
\end{tabular}

\section{Experimental Conditions}

The most influencing turning factors such as feed rate, cutting velocity and depth of cut considered for the experimentation and their levels are indicated in Table 4 . The trials were arranged in view of $\left(3^{3}\right)$ full factorial design in a turning centre (All Geared Lathe), which appeared in Figure 1. The turning action is made on 655M13 cylindrical components of $80 \mathrm{~mm}$ diameter by utilizing TiAlN coated carbide insert in traditionally flooded machining conditions. The photograph of measuring arrangement and surface roughness apparatus is shown in Figure 2a and Figure 2b correspondingly.

The experimental plan and the outcome is given in Table 5 , where, ' $\mathrm{Ra}$ ' is the average surface roughness value of the trials $\mathrm{Ra}_{1}, \mathrm{Ra}_{2}, \mathrm{Ra}_{3}, \mathrm{Ra}_{4}$ of a single machined component, ' $\mathrm{Fm}$ ' is the mean cutting force and ' $\mathrm{T}$ ' is the tool-work interface temperature.

Table 4: Control factors and Levels

\begin{tabular}{|c|l|l|c|c|c|}
\hline \multirow{2}{*}{ Notation } & \multirow{2}{*}{$\begin{array}{c}\text { Turning } \\
\text { factors }\end{array}$} & Unit & \multicolumn{3}{|c|}{ Levels } \\
\cline { 4 - 6 } & $\mathbf{1}$ & $\mathbf{2}$ & $\mathbf{3}$ \\
\hline $\mathrm{v}$ & $\begin{array}{l}\text { Cutting } \\
\text { velocity }\end{array}$ & $\mathrm{m} / \mathrm{min}$ & 225 & 275 & 325 \\
\hline $\mathrm{f}$ & Feed rate & $\mathrm{mm} / \mathrm{rev}$ & 0.1 & 0.15 & 0.2 \\
\hline $\mathrm{d}$ & $\begin{array}{l}\text { Depth of } \\
\text { Cut }\end{array}$ & $\mathrm{mm}$ & 0.2 & 0.4 & 0.6 \\
\hline
\end{tabular}

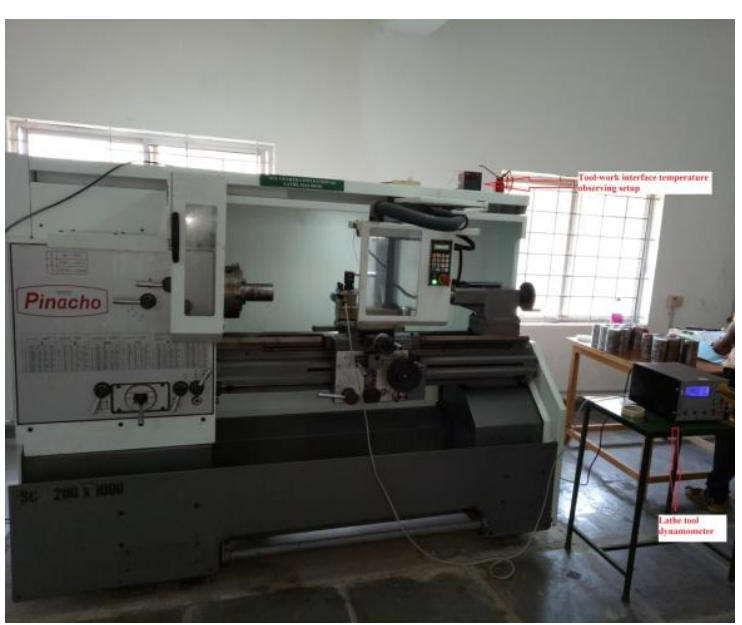

Figure 1: Experimental setup

Published By:

Blue Eyes Intelligence Engineering 


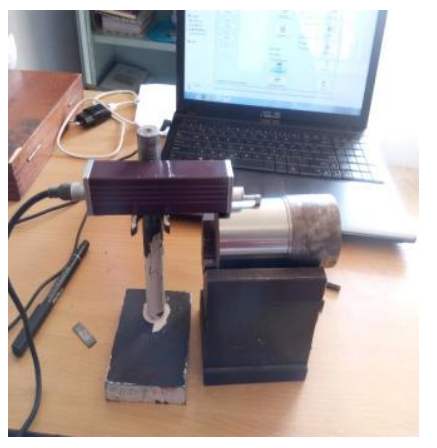

Figure 2a: Photograph of measuring arrangement

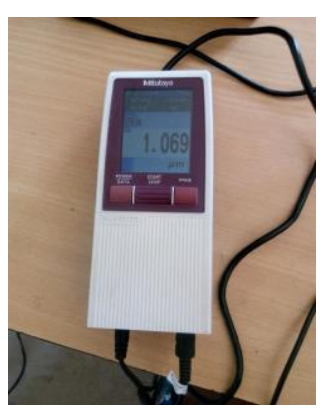

Figure 2b: Surface roughness tester

\section{RESULTS AND DISCUSSION}

\section{A. Experimental plan and results}

$$
F m=\sqrt{ }\left(F a^{2}+F c^{2}+F p^{2}\right)
$$

The mean cutting force $(\mathrm{Fm})$ is calculated using equation (1) respectively.

\section{B. Analysis of variance}

The noteworthy factor on the response output (surface roughness, flank wear, mean cutting force, cutting power and tool-work interface temperature) was analyzed through ANOVA and F-test with a chance of probability $(p=0.05)$, which was shown in Table 6 to Table 8.

The estimation of 'Prob. $>$ F' in Table 6 to Table 8 for the model is under 0.05 , which demonstrates that the representation is important, which is pleasing as it shows that the terms in the representation significantly affect the yield responses (surface roughness, mean cutting force and tool-work interface temperature). From ANOVA comes about, it is obvious that feed rate impacts more on the surface roughness, trailed by the depth of cut and cutting velocity. Similarly, in the case of mean cutting force, the depth of cut is the most influencing factor trail by feed rate and cutting velocity. Similarly, in the case of tool-work interface temperature, cutting velocity is the most influencing factor trail by the depth of cut and feed rate. This is harmonizing with the current hypotheses of machining.

\section{Mathematical model}

By means of regression examination with the aid of MINITAB 17 numerical software, the outcome of control factors on surface roughness (Ra), mean cutting force (Fm) and tool-work interface temperature $(\mathrm{T})$ was modeled as follows;

$R a=1.29783-0.04133 v+0.59498 f+0.16472 d-0.0843 v f+0.0924 v d+0$. 0482fd

$F m=74.83-15.03 v+15.84 f+35.87 \mathrm{~d}-2.17 \mathrm{vf}+2.19 \mathrm{vd}+11.56 \mathrm{fd}$ $\mathrm{T}=108.303+29.50 \mathrm{v}+12.58 \mathrm{f}+14.53 \mathrm{~d}+0.02 \mathrm{vf}+0.02 \mathrm{vd}+0.04 \mathrm{fd}$

For equation (2), equation (3) and equation (4), it was found that the correlation coefficient is above 0.8 , where ' $R$ ' is the correlation coefficient, which shows the nearness of the mathematical representation in lieu of the yield response.

The comparison plot of actual and predicted values of the output responses surface roughness, mean cutting force and tool-work interface temperature are depicted in Figure 3, Figure 4 and Figure 5 respectively.

The average deviation between actual and predicted experimental response values of surface roughness $(\mathrm{Ra})$, mean cutting force $(\mathrm{Fm})$ and tool-work interface temperature (T) is $2.6 \%, 4.5 \%$ and $3.6 \%$ respectively. Since error percentage is lesser than $5 \%$, the mathematical model illustrated in equation (2), equation (3) and equation (4) could be applied whenever 655M13 steel alloy is turned for the typical applications like gears, gear shaft, main axis, valve rods and connecting rods.

\section{Optimum Condition by Genetic Algorithm}

\section{D.1. Genetic Parameters}

MATLAB genetic algorithm solver was used to find the optimum machining condition for the minimization of average surface roughness $(\mathrm{Ra})$, mean cutting force $(\mathrm{Fm})$ and tool-work interface temperature ( $\mathrm{T}$ ) in this study. The mathematical model is given in equation (2), equation (3) and equation (4) was suitably modified for fitness function. The following values of genetic parameters were given as inputs in the MATLAB solver.

\begin{tabular}{|c|c|}
\hline Generation & 10000 \\
\hline Number of variables & 3 \\
\hline Bounds (lower) & {$\left[\begin{array}{lll}1 & 1 & 1\end{array}\right]$} \\
\hline Bounds (upper) & {$\left[\begin{array}{lll}3 & 3 & 3\end{array}\right]$} \\
\hline Selection function & Roulette \\
\hline Elite count & 2 \\
\hline Crossover fraction & Scattered \\
\hline Mutation function & Uniform \\
\hline Mutation rate & 0.1 \\
\hline Migration & : forward \\
\hline Total number of it & 900 \\
\hline Level of display & ve \\
\hline
\end{tabular}

\section{D.2. Genetic Algorithm graphical result}

The genetic algorithm was run for the above-said parameters; it was observed that the fitness value for average surface roughness (Ra), mean cutting force (Fm) and tool-work interface temperature (T) was decreased through generations as shown in Figure 6, Figure 7 and Figure 8 respectively. The optimum average surface roughness of $0.5367 \mu \mathrm{m}$, Mean cutting force of $19.52 \mathrm{~N}$ and optimum tool-work interface temperature of $51.77^{\circ} \mathrm{C}$ was obtained.

\section{E. Effect of machining factors}

The effect of machining factors on surface roughness (Ra), mean cutting force (Fm) and tool-work interface temperature (T) are studied and presented accordingly in the following section. Figure 9 to Figure 17 depicts the surface plots of machining factors on surface roughness $(\mathrm{Ra})$, mean cutting force $(\mathrm{Fm})$ and tool-work interface temperature $(\mathrm{T})$ respectively. Figure 9 depicts the outcome of cutting velocity and feed rate on the mean surface roughness, where the depth of cut is kept constant. From Figure 9 it is so obvious that feed rate and cutting velocity influences more on surface roughness, at minimum feed rate minimum surface roughness was observed, the interaction between feed rate and cutting velocity seems significant on surface roughness. Figure 10 depicts the outcome of feed rate and depth of cut on the mean surface roughness, where cutting velocity is kept constant. From Figure 10 it is obvious that feed rate has the most influence on surface roughness than the depth of cut, at a minimum feed rate and a minimum depth of cut minimum surface roughness could be achieved.




The Outcome of Turning Factors on the Machining Characteristics While Turning 655M13 Steel Alloy using Tialn Coated Carbide Insert

Table 5: Experimental results

\begin{tabular}{|c|c|c|c|c|c|c|c|c|c|c|c|c|c|}
\hline \multirow{2}{*}{$\begin{array}{c}\text { Expt. } \\
\text { run }\end{array}$} & \multicolumn{3}{|c|}{ Turning Parameters } & \multicolumn{5}{|c|}{ Surface Roughness $(\mu \mathrm{m})$} & \multicolumn{4}{|c|}{ Cutting forces $(\mathrm{N})$} & \multirow{2}{*}{$\begin{array}{c}\begin{array}{c}\text { Machining } \\
\text { Temperature }\left({ }^{0} \mathrm{C}\right)\end{array} \\
\text { Actual, } \mathrm{T} \\
\end{array}$} \\
\hline & $\begin{array}{c}\mathrm{v} \\
(\mathrm{m} / \mathrm{min})\end{array}$ & $\begin{array}{c}\mathbf{f} \\
(\mathrm{mm} / \mathrm{rev})\end{array}$ & $\begin{array}{c}\mathrm{d} \\
(\mathrm{mm})\end{array}$ & $\mathbf{R a}_{1}$ & $\mathbf{R a}_{2}$ & $\mathbf{R a}_{3}$ & $\mathbf{R a}_{4}$ & $\begin{array}{c}\text { Mean, } \\
\text { Ra }\end{array}$ & Fa & Fc & Fp & $\begin{array}{c}\text { Mean, } \\
\text { Fm }\end{array}$ & \\
\hline 1 & 225 & 0.1 & 0.2 & 0.5903 & 0.5987 & 0.5926 & 0.5990 & 0.5951 & 11.20 & 24.01 & 44.07 & 51.41 & 50.5 \\
\hline 2 & 225 & 0.1 & 0.4 & 0.6644 & 0.6728 & 0.6653 & 0.6798 & 0.6706 & 16.57 & 31.46 & 67.62 & 76.40 & 65.0 \\
\hline 3 & 225 & 0.1 & 0.6 & 0.7385 & 0.7468 & 0.7153 & 0.7698 & 0.7426 & 21.34 & 40.62 & 98.46 & 108.63 & 79.5 \\
\hline 4 & 225 & 0.15 & 0.2 & 1.2337 & 1.2421 & 1.2696 & 1.2860 & 1.2578 & 11.79 & 27.41 & 52.46 & 60.35 & 66.4 \\
\hline 5 & 225 & 0.15 & 0.4 & 1.4029 & 1.4113 & 1.2054 & 1.2218 & 1.3103 & 13.55 & 35.62 & 73.13 & 82.46 & 80.9 \\
\hline 6 & 225 & 0.15 & 0.6 & 1.5721 & 1.5805 & 1.1412 & 1.1576 & 1.3628 & 27.47 & 51.66 & 105.60 & 120.72 & 95.4 \\
\hline 7 & 225 & 0.2 & 0.2 & 1.8771 & 1.8855 & 1.9466 & 1.9730 & 1.9205 & 18.97 & 41.62 & 57.96 & 73.84 & 80.9 \\
\hline 8 & 225 & 0.2 & 0.4 & 2.1415 & 2.1498 & 1.8824 & 1.9088 & 2.0206 & 24.89 & 47.29 & 89.25 & 104.02 & 95.4 \\
\hline 9 & 225 & 0.2 & 0.6 & 2.4058 & 2.4142 & 1.8182 & 1.8446 & 2.1207 & 35.30 & 85.76 & 131.19 & 160.66 & 109.9 \\
\hline 10 & 275 & 0.1 & 0.2 & 0.5953 & 0.6110 & 0.6850 & 0.6914 & 0.6457 & 4.33 & 8.42 & 37.94 & 39.10 & 85.3 \\
\hline 11 & 275 & 0.1 & 0.4 & 0.7126 & 0.7282 & 0.6208 & 0.6272 & 0.6722 & 10.28 & 20.39 & 38.65 & 44.89 & 99.8 \\
\hline 12 & 275 & 0.1 & 0.6 & 0.8298 & 0.8455 & 0.8143 & 0.8298 & 0.8298 & 18.20 & 38.74 & 76.93 & 88.04 & 114.3 \\
\hline 13 & 275 & 0.15 & 0.2 & 1.1179 & 1.1336 & 1.1254 & 1.1630 & 1.1350 & 3.51 & 6.43 & 24.44 & 25.51 & 86.7 \\
\hline 14 & 275 & 0.15 & 0.4 & 1.3303 & 1.3459 & 1.2978 & 1.3142 & 1.3220 & 12.26 & 20.51 & 40.87 & 47.35 & 101.2 \\
\hline 15 & 275 & 0.15 & 0.6 & 1.5426 & 1.5583 & 1.3157 & 1.2500 & 1.4167 & 19.46 & 37.15 & 79.64 & 90.01 & 115.7 \\
\hline 16 & 275 & 0.2 & 0.2 & 1.6405 & 1.6561 & 1.7035 & 1.6108 & 1.6527 & 9.80 & 21.55 & 40.87 & 47.23 & 99.8 \\
\hline 17 & 275 & 0.2 & 0.4 & 1.9480 & 1.9636 & 1.9748 & 2.0012 & 1.9719 & 23.09 & 55.65 & 63.04 & 87.20 & 114.3 \\
\hline 18 & 275 & 0.2 & 0.6 & 2.2555 & 2.2711 & 1.9106 & 2.1120 & 2.1373 & 33.00 & 87.02 & 110.49 & 144.47 & 129.0 \\
\hline 19 & 325 & 0.1 & 0.2 & 0.5165 & 0.5086 & 0.4993 & 0.5368 & 0.5153 & 2.24 & 5.24 & 19.05 & 19.89 & 108.5 \\
\hline 20 & 325 & 0.1 & 0.4 & 0.7607 & 0.7837 & 0.7132 & 0.7196 & 0.7443 & 8.65 & 18.05 & 44.30 & 48.61 & 123.0 \\
\hline 21 & 325 & 0.1 & 0.6 & 0.9211 & 0.9441 & 0.9633 & 0.9108 & 0.9348 & 23.06 & 46.56 & 64.95 & 83.18 & 137.5 \\
\hline 22 & 325 & 0.15 & 0.2 & 1.0021 & 1.0251 & 1.0045 & 1.0108 & 1.0106 & 0.84 & 4.90 & 34.00 & 34.36 & 127.3 \\
\hline 23 & 325 & 0.15 & 0.4 & 1.2576 & 1.2806 & 1.3902 & 1.3001 & 1.3071 & 10.32 & 20.81 & 41.63 & 47.67 & 141.8 \\
\hline 24 & 325 & 0.15 & 0.6 & 1.5131 & 1.5361 & 1.4831 & 1.5022 & 1.5086 & 24.75 & 51.21 & 72.41 & 92.07 & 156.3 \\
\hline 25 & 325 & 0.2 & 0.2 & 1.4038 & 1.4268 & 1.3931 & 1.4642 & 1.4220 & 7.66 & 17.02 & 29.07 & 34.54 & 138.9 \\
\hline
\end{tabular}




\begin{tabular}{|l|l|l|l|l|l|l|l|l|l|l|l|l|l|}
26 & 325 & 0.2 & 0.4 & 1.7545 & 1.7774 & 1.7602 & 1.7000 & 1.7480 & 17.47 & 37.59 & 48.11 & 63.51 & 153.4 \\
\hline 27 & 325 & 0.2 & 0.6 & 2.1051 & 2.1281 & 2.0030 & 2.0294 & 2.0664 & 34.10 & 81.53 & 113.93 & 144.19 & 168.1 \\
\hline
\end{tabular}

Table 6: Analysis of Variance for mean surface roughness

\begin{tabular}{|c|c|c|c|c|c|c|c|}
\hline Source & DF & Seq SS & Contribution & Adj SS & Adj MS & F-Value & P-Value \\
\hline $\mathrm{v}$ & 1 & 0.03075 & $0.43 \%$ & 0.00460 & 0.00460 & 3.05 & 0.0960 \\
\hline $\mathrm{f}$ & 1 & 6.37206 & $89.28 \%$ & 0.61646 & 0.61646 & 408.91 & 0.0001 \\
\hline $\mathrm{d}$ & 1 & 0.48839 & $6.84 \%$ & 0.01879 & 0.01879 & 12.46 & 0.0020 \\
\hline $\mathrm{v} * \mathrm{f}$ & 1 & 0.08526 & $1.19 \%$ & 0.08526 & 0.08526 & 56.56 & 0.0001 \\
\hline $\mathrm{v}$ d & 1 & 0.10255 & $1.44 \%$ & 0.10255 & 0.10255 & 68.02 & 0.0001 \\
\hline $\mathrm{f} * \mathrm{~d}$ & 1 & 0.02783 & $0.39 \%$ & 0.02783 & 0.02783 & 18.46 & 0.0001 \\
\hline Error & 20 & 0.03015 & $0.42 \%$ & 0.03015 & 0.00151 & & \\
\hline Total & 26 & 7.13700 & $100.00 \%$ & \multicolumn{5}{|c|}{$\mathrm{R}^{2}$ (Adj) -0.99} \\
\hline \multicolumn{7}{|c|}{$\mathrm{R}^{2}-0.99$} & \multicolumn{7}{|c|}{} \\
\hline
\end{tabular}

Table 7: Analysis of Variance for mean cutting force

\begin{tabular}{|c|c|c|c|c|c|c|c|}
\hline Source & DF & Seq SS & Contribution & Adj SS & Adj MS & F-Value & P-Value \\
\hline v & 1 & 4064.8 & $11.04 \%$ & 4064.8 & 4064.8 & 24.15 & 0.0001 \\
\hline f & 1 & 4513.8 & $12.26 \%$ & 4513.8 & 4513.8 & 26.81 & 0.0001 \\
\hline d & 1 & 23164.0 & $62.90 \%$ & 23164.0 & 23164.0 & 137.60 & 0.0001 \\
\hline vf & 1 & 56.3 & $0.15 \%$ & 56.3 & 56.3 & 0.33 & 0.5700 \\
\hline vd & 1 & 57.4 & $0.16 \%$ & 57.4 & 57.4 & 0.34 & 0.5660 \\
\hline fd & 1 & 1603.9 & $4.36 \%$ & 1603.9 & 1603.9 & 9.53 & 0.0060 \\
\hline Error & 20 & 3366.8 & $9.14 \%$ & 3366.8 & 168.3 & & \\
\hline Total & 26 & 36826.9 & $100.00 \%$ & \multicolumn{7}{|c|}{$\mathrm{R}^{2}(\mathrm{Adj})-0.88$} \\
\hline \multicolumn{7}{|c|}{$\mathrm{R}^{2}-0.91$} & \multicolumn{7}{|c|}{} \\
\hline
\end{tabular}

Table 8: Analysis of Variance for tool-work interface temperature

\begin{tabular}{|c|c|c|c|c|c|c|c|}
\hline Source & DF & Seq SS & Contribution & Adj SS & Adj MS & F-Value & P-Value \\
\hline $\mathrm{v}$ & 1 & 15660.1 & $68.72 \%$ & 15660.1 & 15660.1 & 644.68 & 0.0001 \\
\hline $\mathrm{f}$ & 1 & 2846.4 & $12.49 \%$ & 2846.4 & 2846.4 & 117.18 & 0.0001 \\
\hline $\mathrm{d}$ & 1 & 3797.6 & $16.66 \%$ & 3797.6 & 3797.6 & 156.34 & 0.0001 \\
\hline $\mathrm{vf}$ & 1 & 0.0 & $0.00 \%$ & 0.0 & 0.0 & 0.00 & 0.9900 \\
\hline $\mathrm{vd}$ & 1 & 0.0 & $0.00 \%$ & 0.0 & 0.0 & 0.00 & 0.9900 \\
\hline $\mathrm{fd}$ & 1 & 0.0 & $0.00 \%$ & 0.0 & 0.0 & 0.00 & 0.9790 \\
\hline Error & 20 & 485.8 & $2.13 \%$ & 485.8 & 24.3 & & \\
\hline Total & 26 & 22789.8 & $100.00 \%$ & & \multicolumn{5}{|c|}{$\mathrm{R}^{2}(\mathrm{Adj})-0.97$} & \\
\hline \multicolumn{7}{|c|}{$\mathrm{R}^{2}-0.97$} & \multicolumn{5}{|l|}{} \\
\hline
\end{tabular}

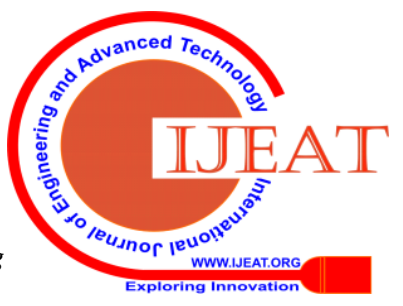


The Outcome of Turning Factors on the Machining Characteristics While Turning 655M13 Steel Alloy using Tialn Coated Carbide Insert
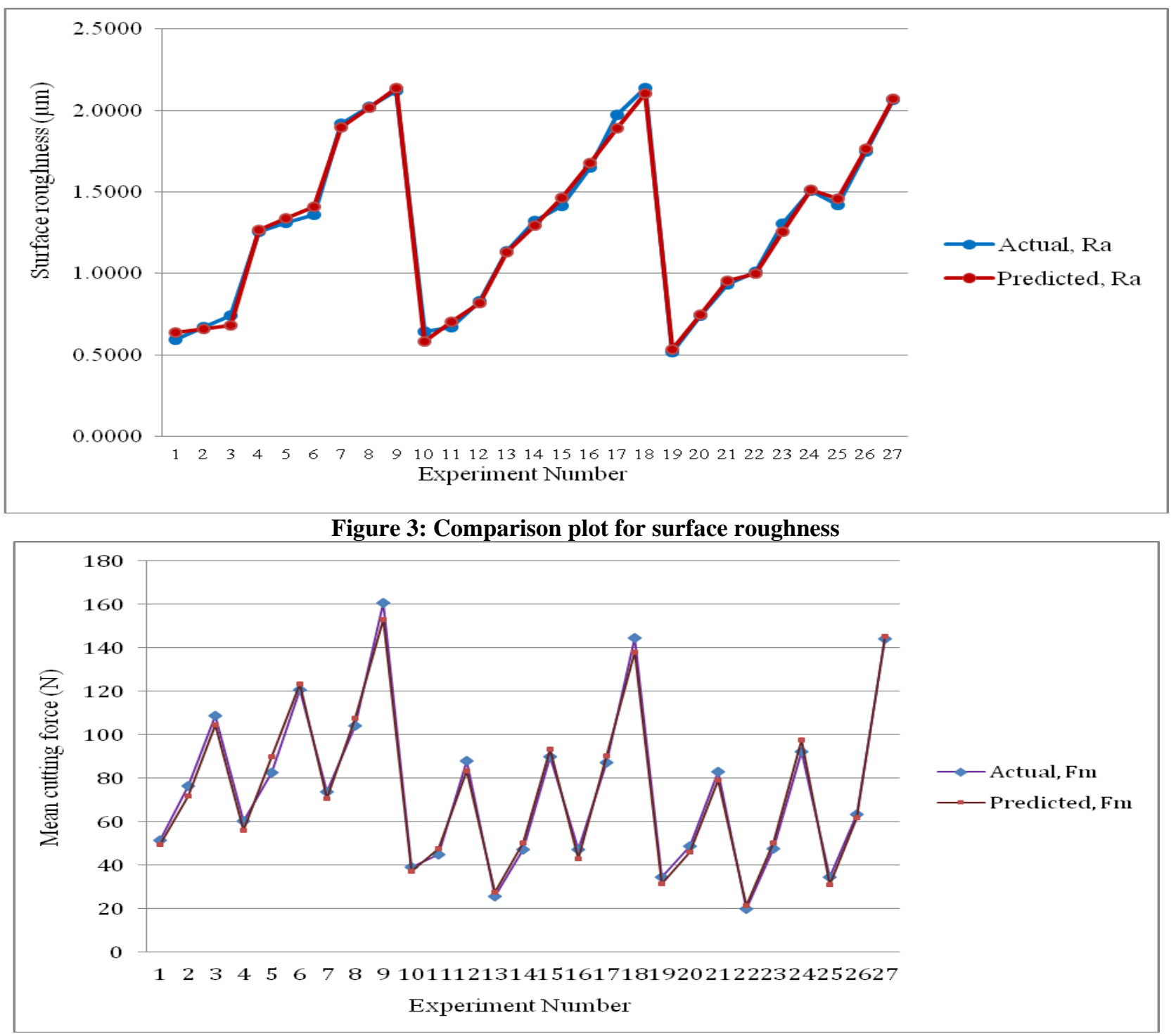

Figure 4: Comparison plot for mean cutting force

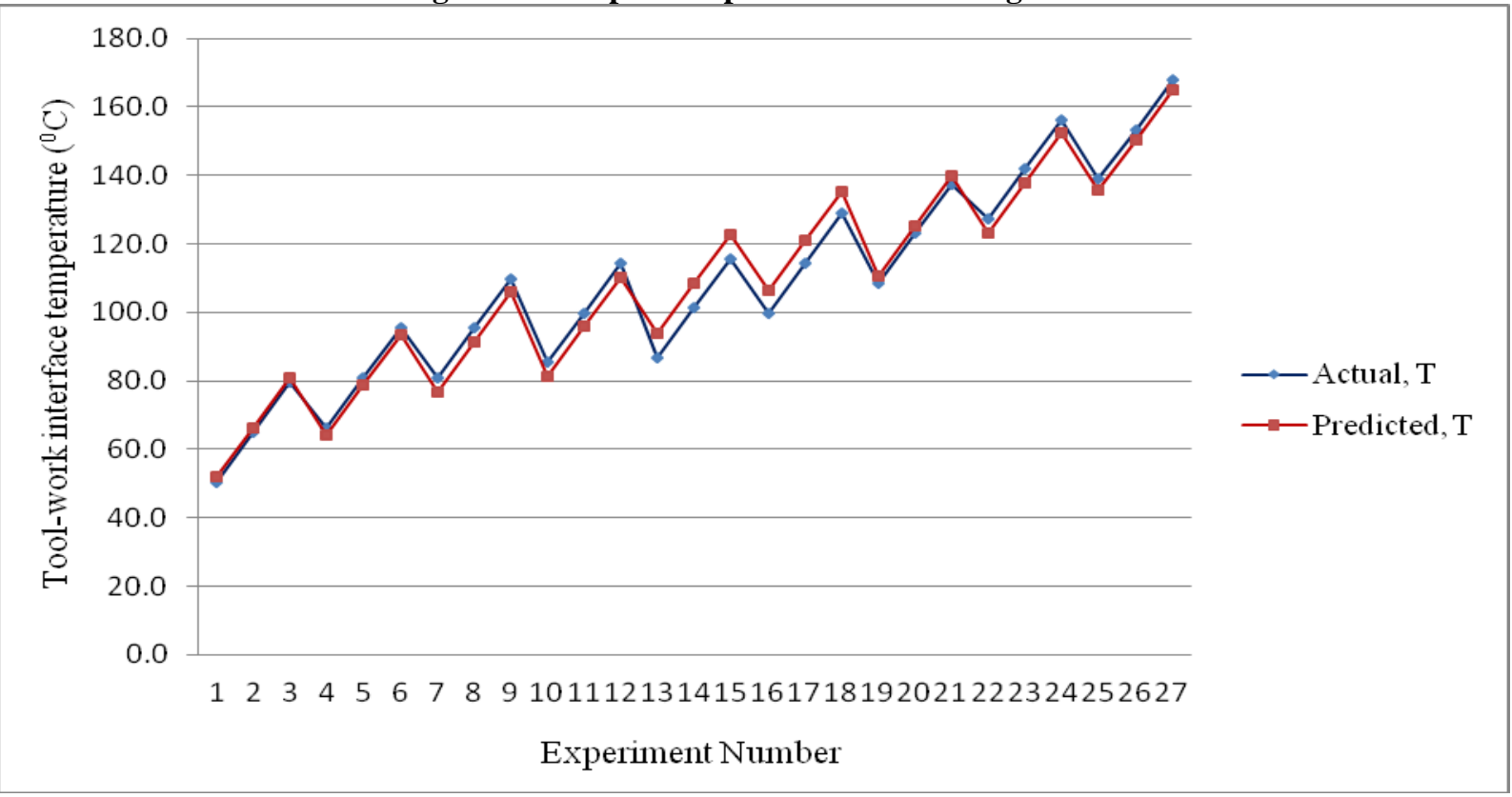

Figure 5: Comparison plot for tool-work interface temperature

Retrieval Number: C5416029320 /2020@BEIESP DOI: 10.35940/ijeat.C5416.029320 Journal Website: www.ijeat.org

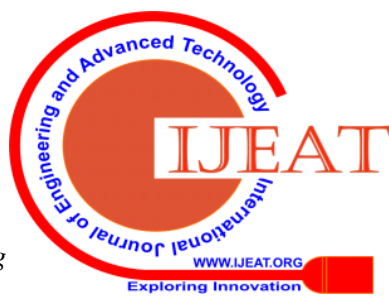



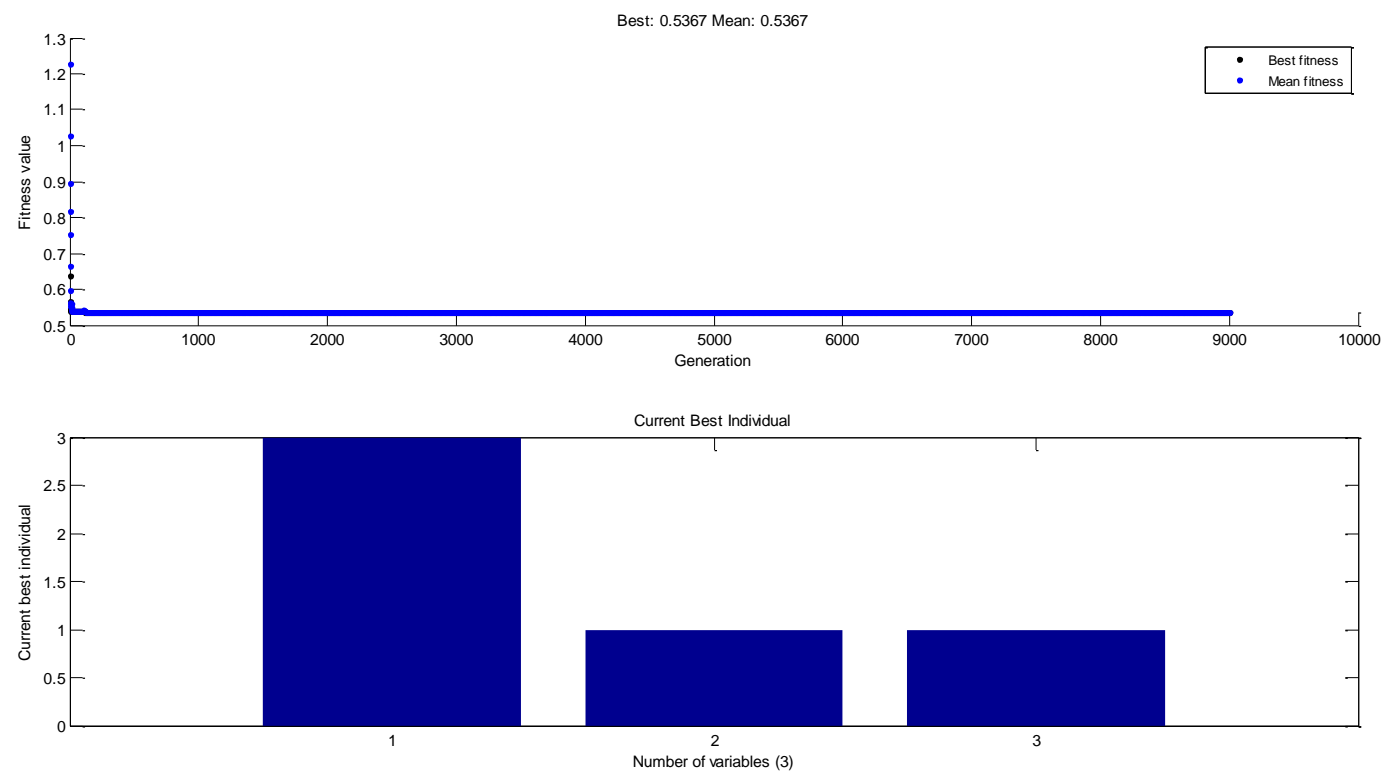

Figure 6: Generation Vs Fitness value for surface roughness


Current Best Individual

Figure 7: Generation Vs Fitness value for mean cutting force
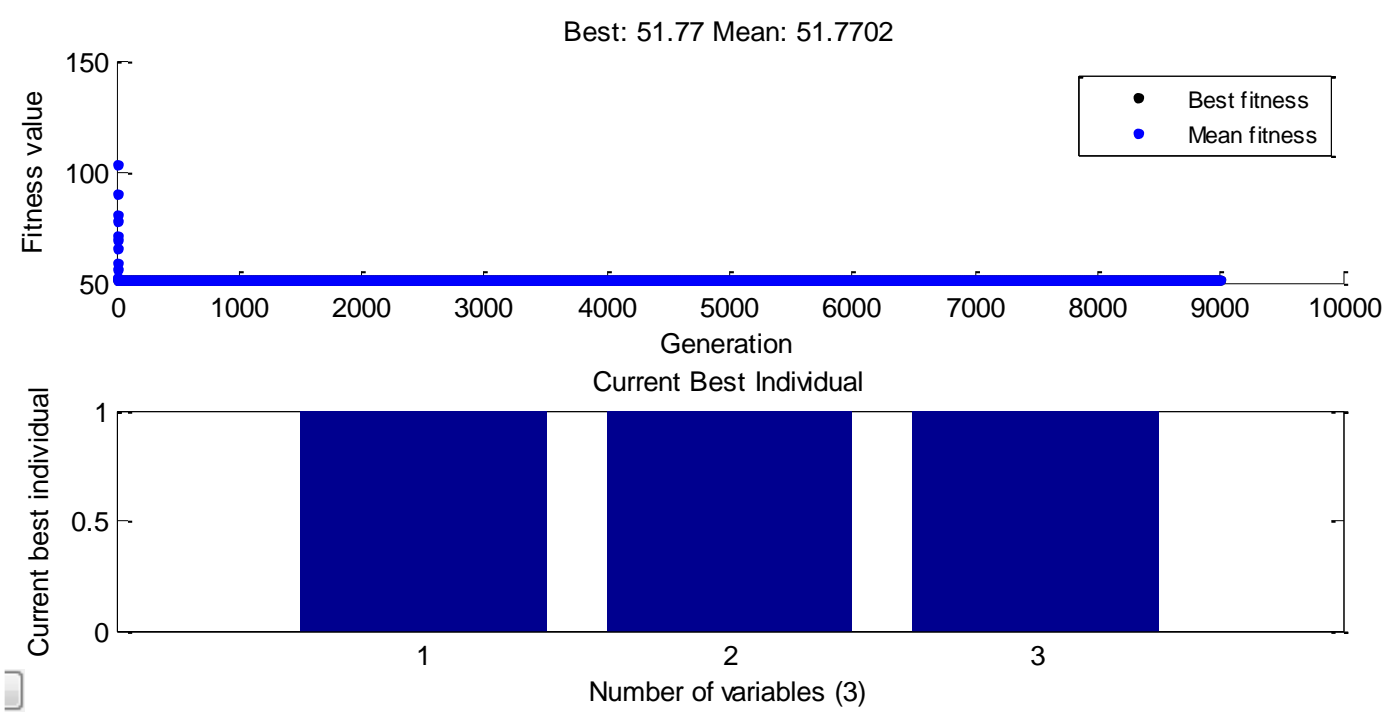

Figure 8: Generation Vs Fitness value for tool-work interface temperature

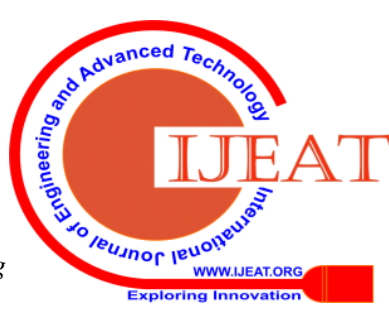


The Outcome of Turning Factors on the Machining Characteristics While Turning 655M13 Steel Alloy using Tialn Coated Carbide Insert

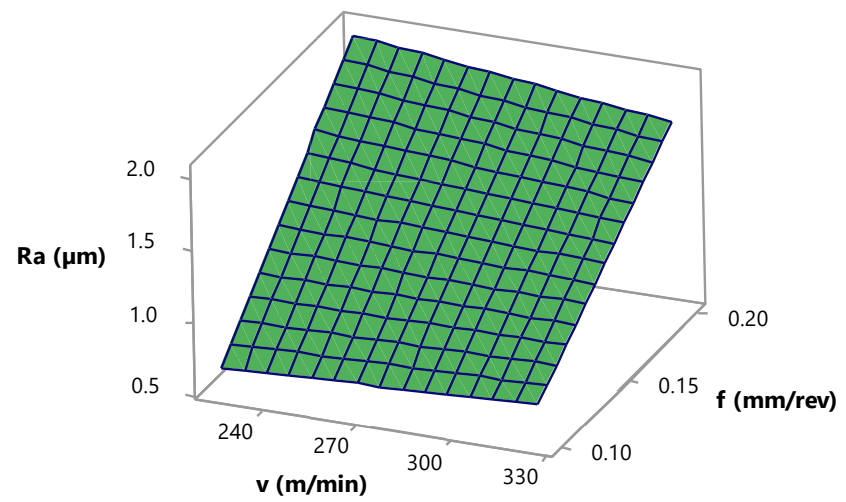

Figure 9: The plot of mean surface roughness versus cutting velocity and feed rate

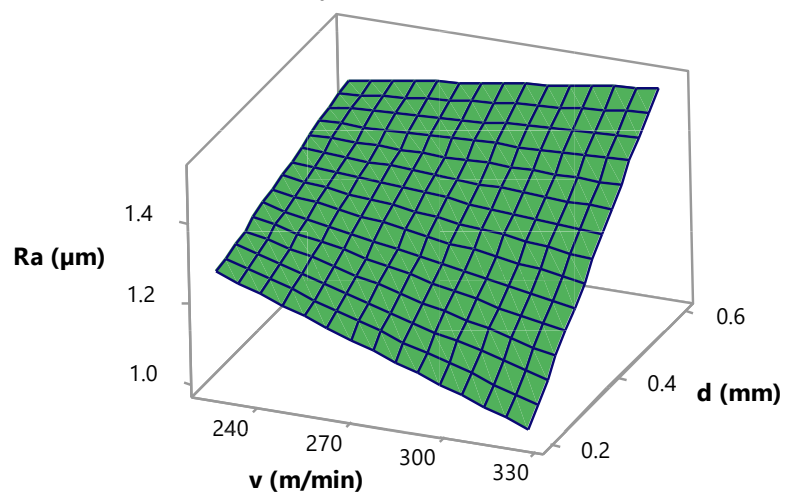

Figure 11: The plot of mean surface roughness versus cutting velocity and depth of cut

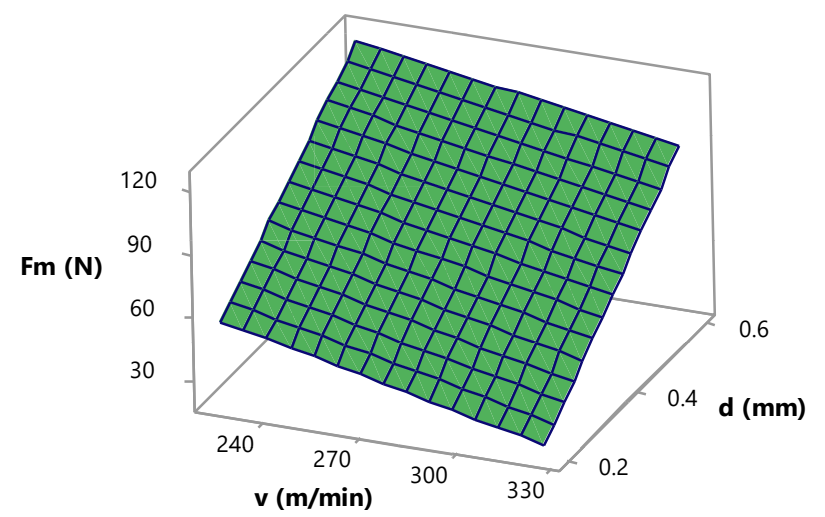

Figure 13: The plot of mean cutting force versus cutting velocity and depth of cut

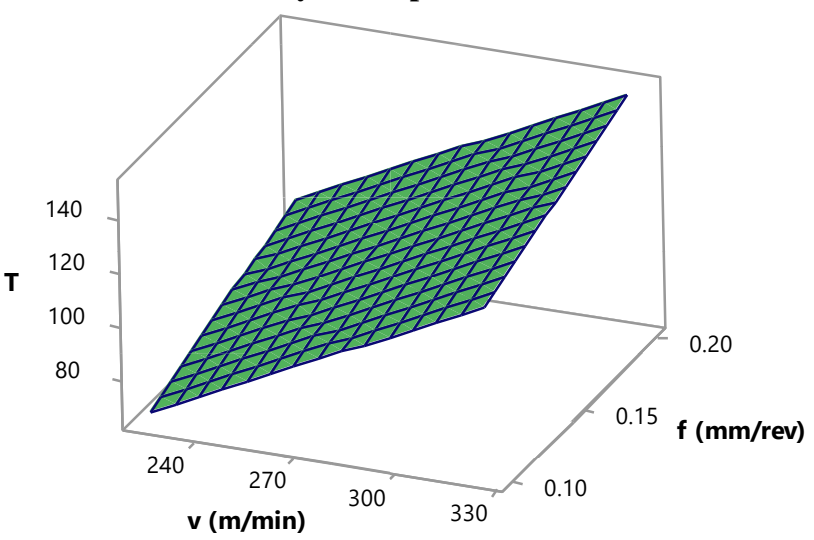

Figure 15: The plot of tool-work interface temperature versus cutting velocity and feed rate

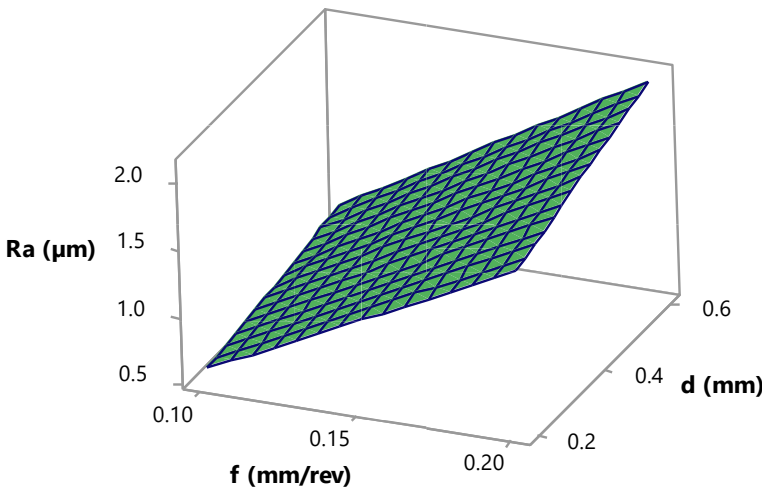

Figure 10: The plot of mean surface roughness versus feed rate and depth of cut

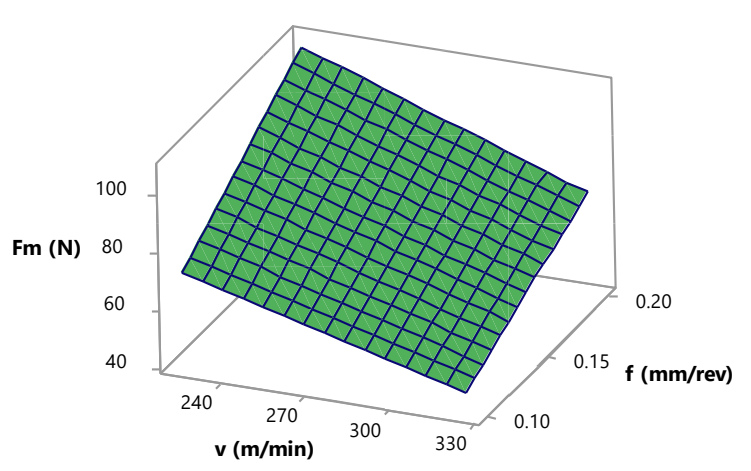

Figure 12: The plot of mean cutting force versus cutting velocity and feed rate

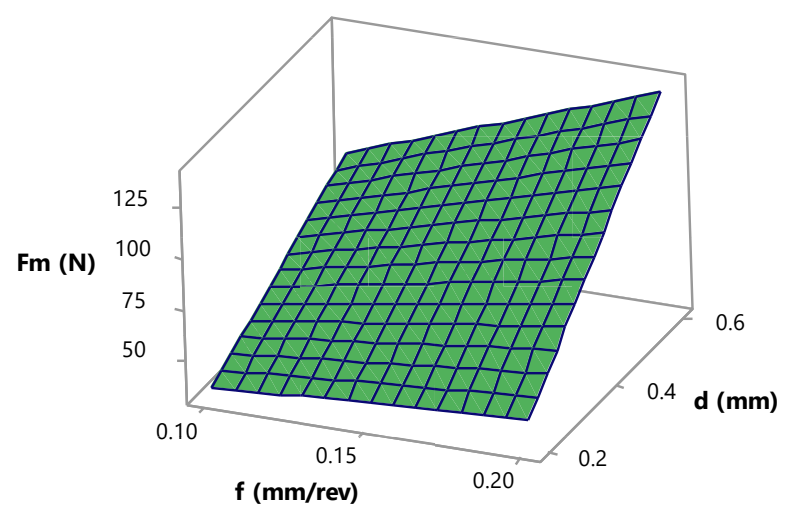

Figure 14: The plot of mean cutting force versus feed rate and depth of cut

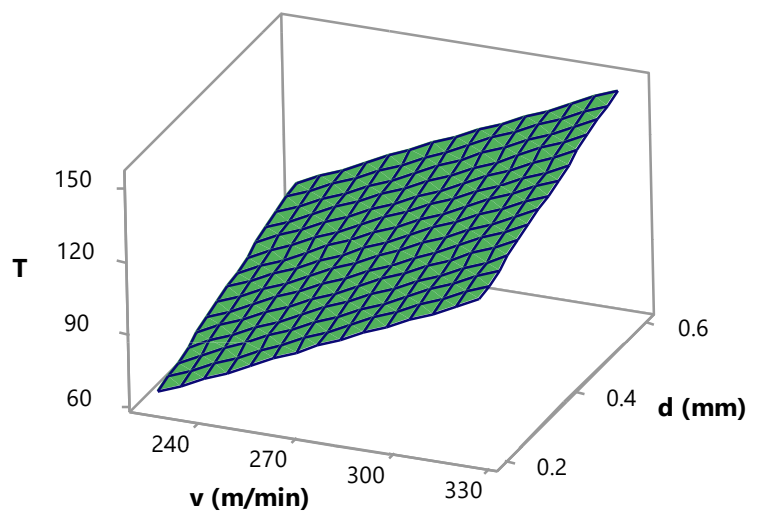

Figure 16: The plot of tool-work interface temperature versus velocity and depth of cut 


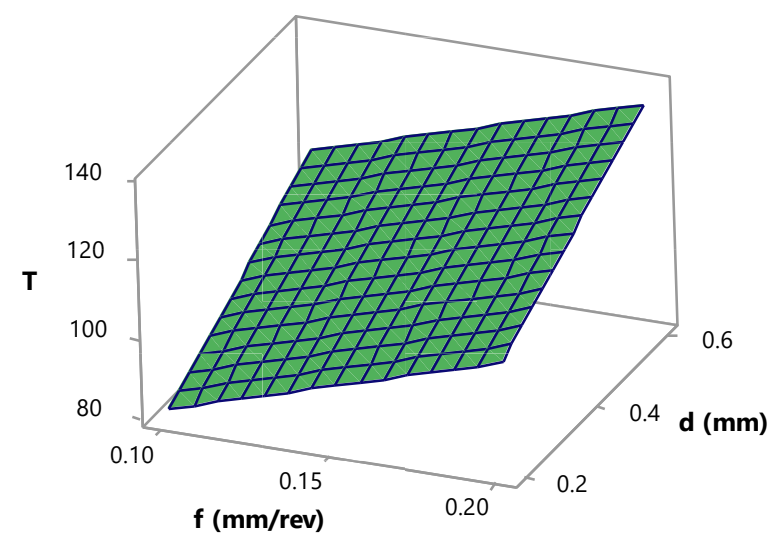

Figure 17: The plot of tool-work interface temperature versus feed rate and depth of cut

Figure 11 depicts the outcome of cutting velocity and depth of cut on the mean surface roughness, where the feed rate is kept constant. From Figure 11 it is obvious that at a maximum cutting velocity and a minimum depth of cut better surface quality products could be produced. Figure 12 depicts the outcome of cutting velocity and feed rate on the mean cutting force, where the depth of cut is kept constant. From Figure 12 it is obvious that feed rate influences more than the cutting velocity, at a minimum feed rate and maximum cutting velocity, the lesser cutting force was observed. Figure 13 portrays the outcome of cutting velocity and depth of cut on the mean cutting force, where the feed rate is kept constant. From Figure 13 it is obvious that the depth of cut influences more than the cutting velocity, at a minimum depth of cut and maximum cutting velocity, the minimum cutting force was observed. Figure 14 depicts the outcome of feed rate and depth of cut on the mean cutting force, where cutting velocity is kept constant. From Figure 14 it is obvious that the depth of cut influences more than feed rate on cutting force, at a maximum feed rate and a maximum depth of cut, increased cutting force was observed. Figure 15 depicts the outcome of cutting velocity and feed rate on the tool-work interface temperature, where the depth of cut is kept constant. From Figure 15 it is so obvious that cutting velocity influences more on tool-work interface temperature than feed rate, the interaction between feed rate and cutting velocity seems significant on tool-work interface temperature. Figure 16 depicts the outcome of cutting velocity and depth of cut on the tool-work interface temperature, where the feed rate is kept constant. From Figure 16 it is obvious that, cutting velocity influences more on tool-work interface temperature than the depth of cut. Figure 17 depicts the outcome of feed rate and depth of cut on the tool-work interface temperature, where cutting velocity is kept constant. From Figure 17 it is obvious that feed rate has the most influence on tool-work interface temperature than the depth of cut.

While machining cylindrical 655M13 steel alloy components in flooded machining conditions, the cutting forces observed axially, tangentially and radially and the corresponding cutting power played a major role. Maximum cutting forces were observed at higher levels of control factors such as $325 \mathrm{~m} / \mathrm{min}$ of cutting velocity, $0.2 \mathrm{~mm} / \mathrm{rev}$ of feed rate and $0.6 \mathrm{~mm}$ of the depth of cut. The cutting forces required for machining might increase in the increase of the control factors namely cutting velocity, feed rate and depth of cut. The increase in cutting forces ultimately reduces the tool life, which reflects poorly in the production economy.

\section{CONCLUSIONS}

In this background, the study reported in this paper was surface roughness and flank wear test conducted during turning operation of 655M13 steel with TiAlN coated cutting tool insert in flooded coolant condition. The following conclusions were drawn out from the present examination;

i. The ANOVA and F-test of the experimented results exposed that feed rate impacts more on the surface roughness, trailed by the depth of cut and cutting velocity. Similarly, in the case of mean cutting force, the depth of cut is the most influencing factor trail by feed rate and cutting velocity. Similarly, in the case of tool-work interface temperature, cutting velocity is the most influencing factor trail by the depth of cut and feed rate. This is harmonizing with the current hypotheses of machining.

ii. Generalized mathematical models were developed through regression analysis using Minitab statistical software for the mean surface roughness ( $\mathrm{Ra}$ ), mean cutting force (Fm) and tool-work interface temperature (T). From those equations, the mean surface roughness, mean cutting force and tool-work interface temperature values could be calculated if the factors namely feed rate, cutting velocity and depth of cut are known.

iii. The average deviation between actual and predicted experimental response values of surface roughness (Ra) mean cutting force $(\mathrm{Fm})$ and tool-work interface temperature (T) is $2.6 \%, 4.5 \%$ and $3.6 \%$ respectively.

iv. From the experimentation, it is clear that, at a maximum cutting velocity of $325 \mathrm{~m} / \mathrm{min}$, the minimum feed rate of $0.1 \mathrm{~mm} / \mathrm{rev}$ and a minimum depth of cut of $0.2 \mathrm{~mm}$, the minimum surface roughness of $0.5153 \mu \mathrm{m}$ was achieved, minimum surface roughness is the sign of better quality machined components. The optimum condition for a mean cutting force such as $325 \mathrm{~m} / \mathrm{min}$ of cutting velocity, $0.15 \mathrm{~mm} / \mathrm{rev}$ of feed rate and $0.2 \mathrm{~mm}$ of depth of cut.

v. The optimum machining conditions for average surface roughness, mean cutting force and tool-work interface temperature were confirmed with the Genetic algorithm.

vi. The optimum turning conditions found in this research work can be used when 655M13 steel alloy is turned for the typical applications like mechanical gears, gear shaft, main axis, valve rods and connecting rods.

\section{Nomenclature}
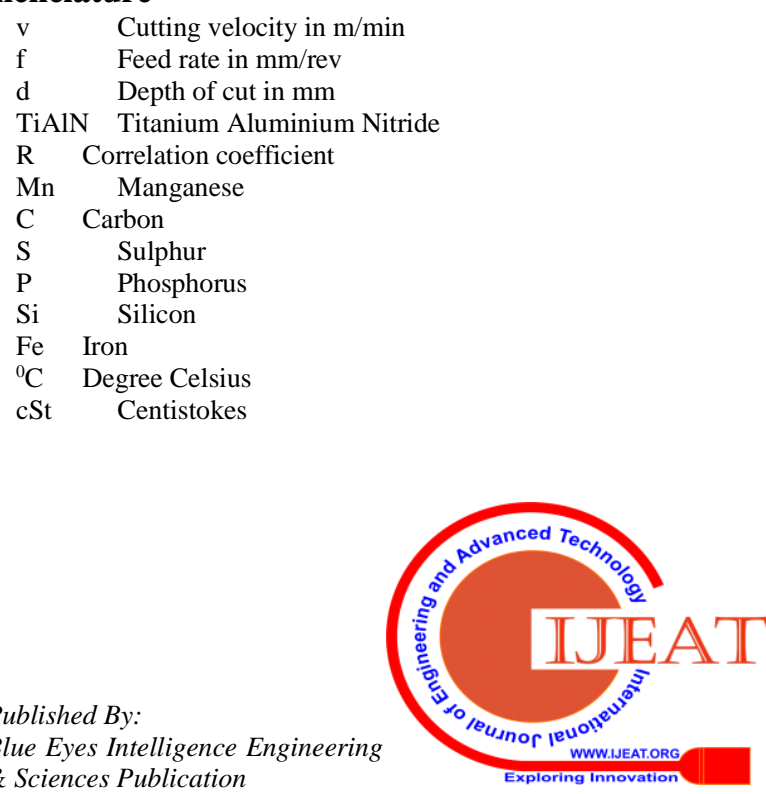
PCLNR ISO designation for the tool holder AISI American Iron and Steel Institute CNMG ISO designation for tool

\section{REFERENCES}

1. Aggarwal, A., Singh, H., Kumar, P. and Singh, M., 2008. Optimizing power consumption for CNC turned parts using response surface methodology and Taguchi's technique-a comparative analysis. Journal of materials processing technology, 200(1-3), pp.373-384.

2. Asiltürk, I., Neşeli, S. and Ince, M.A., 2016. Optimisation of parameters affecting surface roughness of Co28Cr6Mo medical material during CNC lathe machining by using the Taguchi and RSM methods. Measurement, 78, pp.120-128.

3. Bains, P.S., Sidhu, S.S. and Payal, H.S., 2016. Fabrication and machining of metal matrix composites: a review. Materials and Manufacturing Processes, 31(5), pp.553-573.

4. Bhattacharya, A., Das, S., Majumder, P. and Batish, A., 2009. Estimating the effect of cutting parameters on surface finish and power consumption during high speed machining of AISI 1045 steel using Taguchi design and ANOVA. Production Engineering, 3(1), pp.31-40.

5. Cakir, M.C., Ensarioglu, C. and Demirayak, I., 2009. Mathematical modeling of surface roughness for evaluating the effects of cutting parameters and coating material. Journal of materials processing technology, 209(1), pp.102-109.

6. Khan, P.L. and Bhivsane, S.V., 2018. Experimental analysis and investigation of machining parameters in finish hard turning of AISI 4340 steel. Procedia Manufacturing, 20, pp.265-270.

7. Khorasani, A.M., Gibson, I., Goldberg, M., Nomani, J. and Littlefair, G., 2016. Machinability of Metallic and Ceramic Biomaterials: A review. Science of Advanced Materials, 8(8), pp.1491-1511.

8. Krolczyk, G.M., Nieslony, P., Maruda, R.W. and Wojciechowski, S., 2017. Dry cutting effect in turning of a duplex stainless steel as a key factor in clean production. Journal of cleaner production, 142, pp.3343-3354.

9. Mia, M. and Dhar, N.R., 2016. Prediction of surface roughness in hard turning under high pressure coolant using Artificial Neural Network. Measurement, 92, pp.464-474.

10. Mia, M. and Dhar, N.R., 2017. Optimization of surface roughness and cutting temperature in high-pressure coolant-assisted hard turning using Taguchi method. The International Journal of Advanced Manufacturing Technology, 88(1-4), pp.739-753.

11. Nur, R., Noordin, M.Y., Izman, S. and Kurniawan, D., 2017. Machining parameters effect in dry turning of AISI 316L stainless steel using coated carbide tools. Proceedings of the Institution of Mechanical Engineers, Part E: Journal of Process Mechanical Engineering, 231(4), pp.676-683.

12. Paul, P.S., Varadarajan, A.S. and Gnanadurai, R.R., 2016. Study on the influence of fluid application parameters on tool vibration and cutting performance during turning of hardened steel. Engineering Science and Technology, an International Journal, 19(1), pp.241-253.

13. Selvam, M.D. and Senthil, P., 2016. Investigation on the effect of turning operation on surface roughness of hardened C45 carbon steel. Australian Journal of Mechanical Engineering, 14(2), pp.131-137.

14. Selvam, M.D. and Sivaram, N.M., 2017. The effectiveness of various cutting fluids on the surface roughness of AISI 1045 steel during turning operation using minimum quantity lubrication system. i-Manager's Journal on Future Engineering and Technology, 13(1), p.36.

15. Selvam, M.D., Senthil, P. and Sivaram, N.M., 2017. Parametric optimisation for surface roughness of AISI 4340 steel during turning under near dry machining condition. International Journal of Machining and Machinability of Materials, 19(6), pp.554-569.

16. Sharma, A.K., Tiwari, A.K. and Dixit, A.R., 2016. Effects of Minimum Quantity Lubrication (MQL) in machining processes using conventional and nanofluid based cutting fluids: A comprehensive review. Journal of Cleaner Production, 127, pp.1-18.

17. Xiao, Z., Liao, X., Long, Z. and Li, M., 2017. Effect of cutting parameters on surface roughness using orthogonal array in hard turning of AISI 1045 steel with YT5 tool. The International Journal of Advanced Manufacturing Technology, 93(1-4), pp.273-282.

18. Yang, A., Han, Y., Pan, Y., Xing, H. and Li, J., 2017. Optimum surface roughness prediction for titanium alloy by adopting response surface methodology. Results in physics, 7, pp.1046-1050.

19. Zerti, O., Yallese, M.A., Khettabi, R., Chaoui, K. and Mabrouki, T., 2017. Design optimization for minimum technological parameters when dry turning of AISI D3 steel using Taguchi method. The
International Journal of Advanced Manufacturing Technology, 89(5-8), pp.1915-1934.

20. Zhang, P. and Liu, Z., 2017. On sustainable manufacturing of Cr-Ni alloy coatings by laser cladding and high-efficiency turning process chain and consequent corrosion resistance. Journal of cleaner production, 161, pp.676-687.

\section{AUTHORS PROFILE}

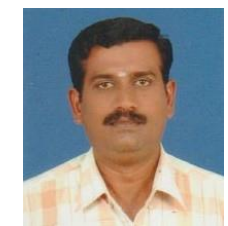

Venkatesh.P has obtained his bachelor in Mechanical Engineering from Bharathiar University and master degree in Mechanical Engineering from Anna University and currently working for his research in the field of machining in Karpagam Academy of Higher Education as a research scholar. His area of interest includes machining of steel and parameter optimization.

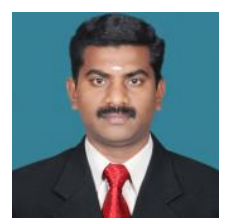

C. Ramesh Kannan has obtained his bachelor's, master's and Ph.D. in Mechanical Engineering from Anna University and Ph.D. from Karpagam Academy of Higher Education. His area of interest includes machining of steel and parameter optimization. He has about 19 years of teaching experience and 8 years of research experience. He has various publications in both national and international journals. He is currently working as an Associate Professor in the Department of Mechanical Engineering, Karpagam Academy of Higher Education, Coimbatore, India. His area of interest includes machining of steel in the cryogenic environment and parametric optimisation.

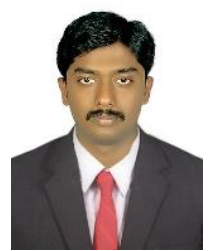

Milon Selvam Dennison received his BTech degree in Mechanical Engineering from Bharath Institute of Higher Education and Research, Chennai, India, ME degree in Manufacturing Engineering from Anna University, India and a Ph.D. degree from Karpagam Academy of Higher Education, India in 2007, 2009 and 2018 respectively. Presently, he is doing research in the field of metal cutting fluids. He has various publications in both national and international journals. He is currently working as Senior Lecturer in the Department of Mechanical Engineering, Kampala International University, Uganda. His current research interests include manufacturing of materials, metal cutting, metal cutting fluids and machining optimisation 